\title{
THE HYDRAULIC MODEL AS AN AID IN BREAKWATER DESIGN
}

\author{
Robert Y. Hudson and L. Frank Moore \\ Respectively, Chief, and Hydraulic Engineer, Wave Action Section \\ Waterways Experiment Station \\ Corps of Engineers, Department of the Army \\ Vicksburg, Mississippi
}

\section{INTRODUCTION}

The complexity of wave-action phenomena and the complicated geometry of most harbors usually make it impossible to obtain adequate answers to design problems by an analytical approach. Except for the most elementary wave-action problems, the general experlence and juagment of the engineer cannot be ut Indeed, this method of approach to harbor problems has led to designs which not only falled to alleviate wave-action conditions, but, instead, actually intensifled them. It is the intent of this paper to show how the small-scale hydraulic model can be an effective tool in the planning of harbor development and in the design and layout of breakwaters to provide protection from wave action.

\section{TYPES OF WAVE-ACTION MODELS}

Wave-action models can be divided into two general types: (1) harbor models, and (2) breakwater stability models. Harbor models usually reproduce the entire harbor area and the various shore-line structures, together with sufficient area seaward to allow proper generation of waves. This type model is used to determine the best solution to wave- and surge-action problems involving the selection of the most efficient type, length and alignment of breakwaters, the location, alignment, shape, and width of navigation openings, the proper location and type of - plers and spending beaches, and the effects of proposed dredging projects. Thus, the harbor model has to do with the solution of problems involving the effects of contemplated changes in static boundary conditions on wave reflection, refraction, diffraction, and attenuation.

Breakwater stability models are useful in selecting the most efficlent design of breakwaters with respect to the forces imposed upon them by wave action. This type model is used to determine the shape and magnitude of wave pressure curves on impervious, vertical and inclined walls, the stablilty of caissons and cribs, and the proper size and density rock, degree of slope, crown elevation and crosssectional shape of rubble-mound breakwaters.

\section{DESIGN OF WAVE-ACTION MODELS}

In nature, surface wind waves and long-period, surge waves are propagated by the restoring force of gravity and are classifled, therefore, as gravity waves. The forces of surface tension and friction are not usually significant for nature waves and can be 1gnored. Waves in smal1-scale models are gravity waves also, and the model is designed, operated, and the test results converted to prototype values on the basis of transference equations derlved from Froude's model law. Further, the model must be constructed geometrically similar to its prototype if dynamic similarity is required. After the linear scale $\left(I_{r}\right)$ has been selected, based on considerations to be explained in subsequent paragraphs, the remaining scales can be derived from Froude's number and simple geometrical principles. For an undistorted model, these scales are shown as follows:

\begin{tabular}{|c|c|c|c|c|c|}
\hline & & Scales, Model & & & Scales, Model \\
\hline Characteristics & Dimensions* & to Prototype & Characteristics & D1mensions* & to Prototype \\
\hline Area & $\mathrm{I}^{2}$ & $A_{r}=I_{r^{2}}$ & Force & $F$ & $F_{r}=I_{r} 3 \gamma_{r^{* *}}$ \\
\hline Volume & L3 & $\bar{V}_{r}=I_{r} 3$ & Weight & $F$ & $W_{r}=L_{r} 3 \gamma_{r}$ \\
\hline Time & $\mathrm{T}$ & $\mathrm{T}_{\mathrm{r}}=\mathrm{L}_{\mathrm{r}} 1 / 2$ & Unit pressure & $F / L^{2}$ & $P_{r}=I_{r} r_{r}$ \\
\hline Velocity & $\mathrm{L} / \mathrm{T}$ & $\mathrm{V}_{\mathrm{r}}=\mathrm{I}_{\mathrm{r}} 1 / 2$ & Energy & FL & $E_{r}=L_{r}{ }^{4} \gamma_{r}$ \\
\hline
\end{tabular}




\section{COASTAL ENGINEERING}

Although the force of gravity predominates in the propagation of nature waves, this may not be true for model waves unless the linear scale of the model is chosen judiclously. If this scale is too small, the forces of surface tension and friction may become of such magnitude, In relation to the force of gravity, that accurate reproduction of wave phenomena will not be obtalned. In harbor wave-action studies the wave characteristics which must be reproduced accurately are wave patterns and corresponding wave amplitudes. Since the $d / I$ ratio affects wave velocity, and thus wave patterns and amplitudes, over a considerable range of this ratio, it is not possible to distort the linear scale of this type model except in special cases.

Distorted-scale harbor models can be used if the waves in nature are elther deep-water waves or waves of translation. The degree of distortion allowable is Iimited to this extent: If the waves are deep-water waves in nature, they must be deep-water waves in the model. Simllarly, if the waves in nature are waves of translation, they must be waves of translation in the model. In general, shortperiod wind waves can seldom be studied by use of distorted-scale models, whereas in the case of Iong-period surge waves, scale distortion, if not too great, will not affect the accuracy of model results. Fig. I shows the effects of surface tension, internal friction, boundary friction, and scale distortion on the propagation of waves. These curves, the equations for which can be found in theoretical hydrodynamics texts (Lamb, 1932) and in papers by Keulegan (1950a, 1950b), are very useful in designing smal1-scale harbor models. Fig. 1 (a) and $1(b)$ show that surface tension and internal friction are not critical and will not affect the selec-

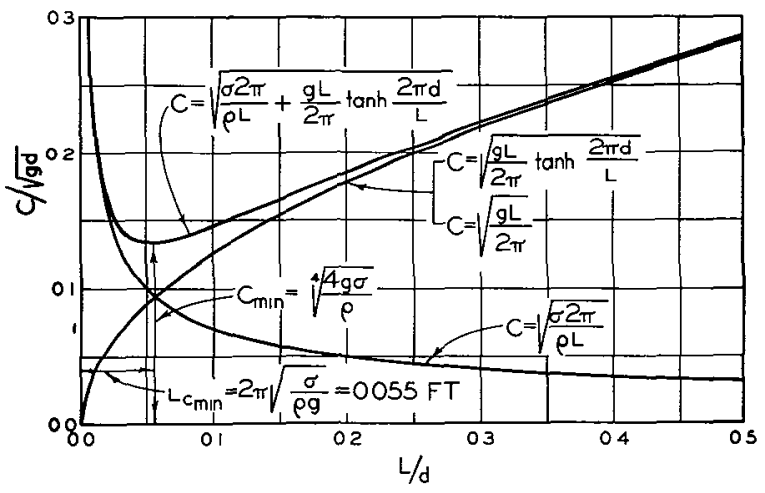

(a) EFFECT OF SURFACE TENSION

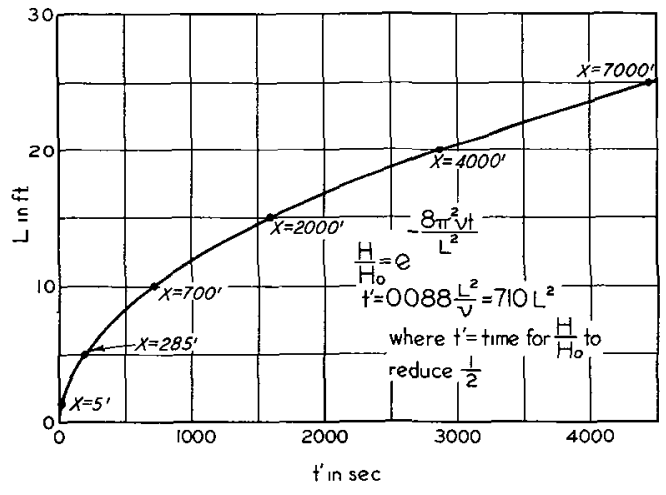

(b) EFFECT OF INTERNAL FRICTION

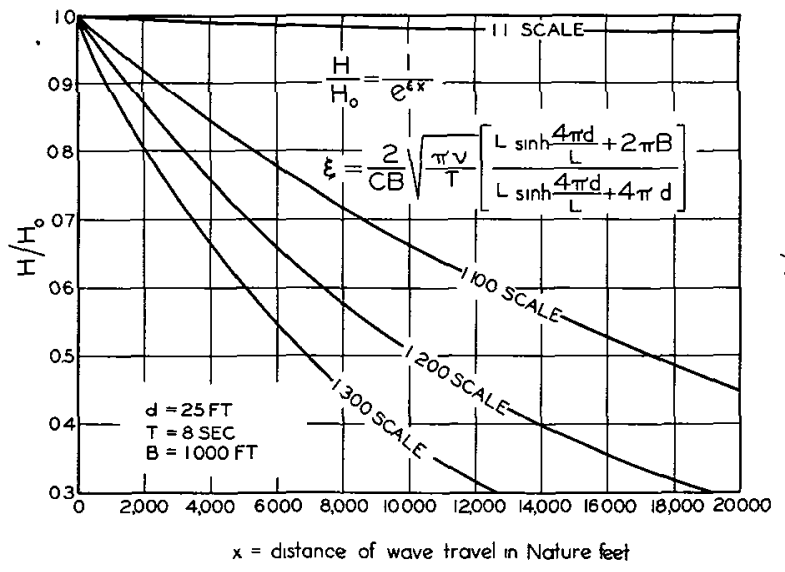

(c) EFFECT OF BOUNDARY FRICTION

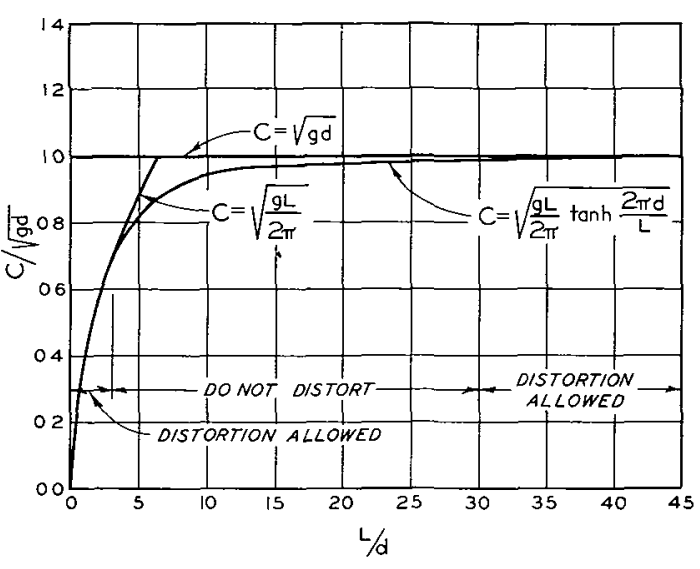

(d) EFFECT OF SCALE DISTORTION

Fig. 1. Design of wave action models. 
tion of scale unless very large prototype areas are to be reproduced in a very small scale model. Fig. $I(c)$ and $1(d)$ show, however, that boundary friction and scale distortion can affect appreclably the accuracy of model results, and these factors should be given careful examination before the scales of harbor wave-action models are selected. In breakwater stabllity models it is necessary to reproduce the dynamic characteristics of the waves and the resisting forces of the breakwater material. Therefore, scale distortion is not possible in these models.

Economical considerations require the selection of the smallest model scale consistent with the desired accuracy of model results. The degree of accuracy which can be obtained by use of scale models is determined by the laws of similitude, as explained above, the exactness of model construction and the accuracy with which the characteristic wave dimensions can be generated and measured. Therefore, these considerations, tempered by the funds avallable, determine the model scale selected.

\section{TYPICAL HARBOR MODELS}

The most common types of harbor models are those having to do with long-period surge waves and those in which the principal problem is caused by short-period wind waves. An example of the former is the model study of Long Beach Harbor, which was performed by the Waterways Experiment Station (1949c) for the City of Long Beach, California. Since this study was described by Thorley (1950), it will not be discussed in detail here. The main problem concerned the effects of contemplated pier extensions on surge action in the existing Long Beach Harbor and selection of the best plan for the proposed additional harbor basin immediately southeast of Long Beach Harbor. An existing distorted-scale model (horizontal scale 1:300 and vertical scale 1:60) of the San Pedro Bay area was utilized for this study. It was not possible to develop an ideal solution to the problem at Long Beach because of the wide spread in the spectrum of waves existing in the San Pedro area, which made it impossible to eliminate entirely the conditions of resonance between the periods of the waves and the natural oscillating periods of the basin waters. The most critical periods of resonance for each inner-harbor basin were determined by frequency-response tests in which the magnitudes of disturbances inside the basins were compared with those of the exciting wave trains for periods up to about six minutes. Waves with these periods were then generated in the model from various directions outside the outer breakwater, and the modes of oscillation in the outer harbor which resulted in the worst conditions in the inner basins were determined. The inner-harbor basins studied in this manner were the existing Navy-Long Beach Harbors and the southeast-basin harbor proposed by the City of Long Beach. Since the existing Navy-Long Beach Harbor is known to be very satlsfactory with respect to long-period surge action, the results of new plans were analyzed by comparison.

A typical example of a harbor model concerned with the effects of short-period wind waves is that of oswego Harbor, Lake Ontario, New York (Waterways Experiment Station, 1949a). The purpose of this model was to determine whether the proposed plan of harbor improvement would be adequate to protect the harbor from wave action, and, if it were not, to devise a plan which would provide sufficient protection at minimum cost. The study was conducted in a concrete model geometrically similar to its prototype with an undistorted linear scale of $1: 100$. As can be seen in Fig. 2, the harbor is exposed to wind waves generated by storms from all directions between west and northeast. Storms occur most frequently from the directions west to northwest, where fetches, wind speeds, and resulting wave heights are greatest. Because of the harbor's physical layout, however, storms from the area north-northwest to north-northeast are the most critical. The large waves from the west are refracted harmlessly onto a spending beach inside the harbor. The deep-water dimensions of model-test waves were selected by applying SverdrupMunk curves (Arthur, 1948) to prototype wind data; these test waves were then charted into the various wave-machine positions by refraction diagrams (Johnson, o'Brien, and Isaacs, 1948). Various lengths and alignments of breakwaters were tested. The existing arrowhead breakwater and an arrowhead wave-trap form of detached breakwater were found to be ineffective against northerly waves, due to a submarine ridge in the outer harbor which caused convergence of wave orthogonals at the navigation opening. 

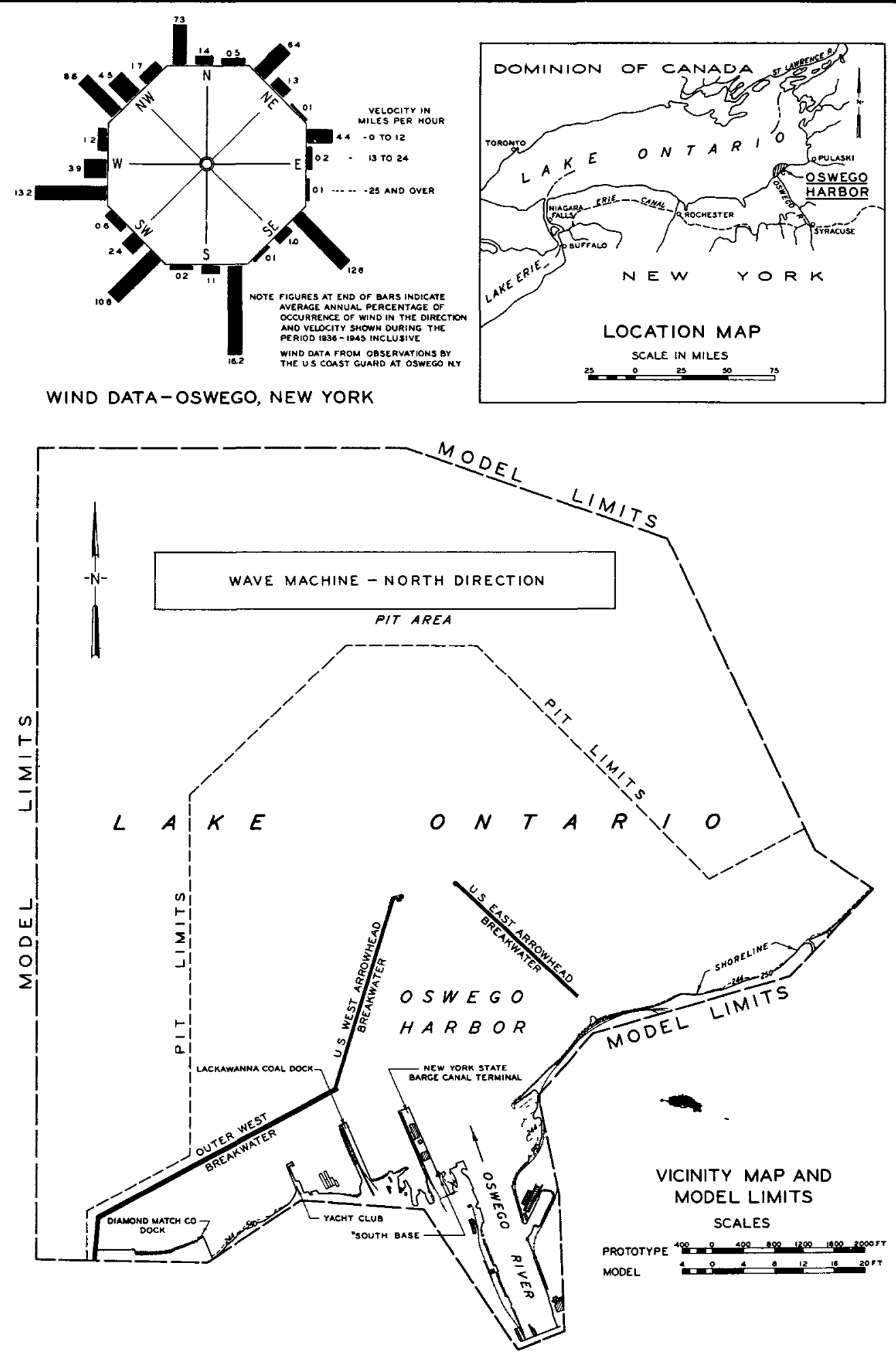

Fig. 2. Model study of Oswego Harbor 
It was concluded from the results of the model study that: (1) the originally proposed plan would not have been adequate and, instead, would have intensified wave action conditions in the harbor; (2) a breakwater plan developed during the model study, similar to the originally proposed plan except for slight differences in length and alignment, would be satisfactory; (3) an artificial spending beach should be constructed at the southeast corner of the New York State Barge Canal Terminal; (4) an alternate breakwater plan developed during the model study would afford more effective protection from wave action than any of the other plans, but the cost of constructing this plan might be prohibitive; and (5) the existing impervious, vertical-walled wharf's in oswego Harbor magnify the action of waves that gain entrance into the harbor through the navigation opening, making it desirable to avold this type of construction for additional wharfs or other harbor structures unless the structures are to be located in harbor areas amply protected from wave action.

\section{A TYPICAI BREAKWATER MODEL}

A 1:30-scale model study was performed recently at the Waterways Experiment Station to determine the relative stability and maintenance costs of two types of rubble breakwaters proposed for use at East Beaver Bay Harbor, Lake Superior, Minnesota (Waterways Experiment Station, 1949b). Details of these breakwaters are shown in Fig. 3. Economy prescribed end and side dumping of rock quarried at the breakwater site. This in turn required stability tests to determine the most efficlent breakwater section.

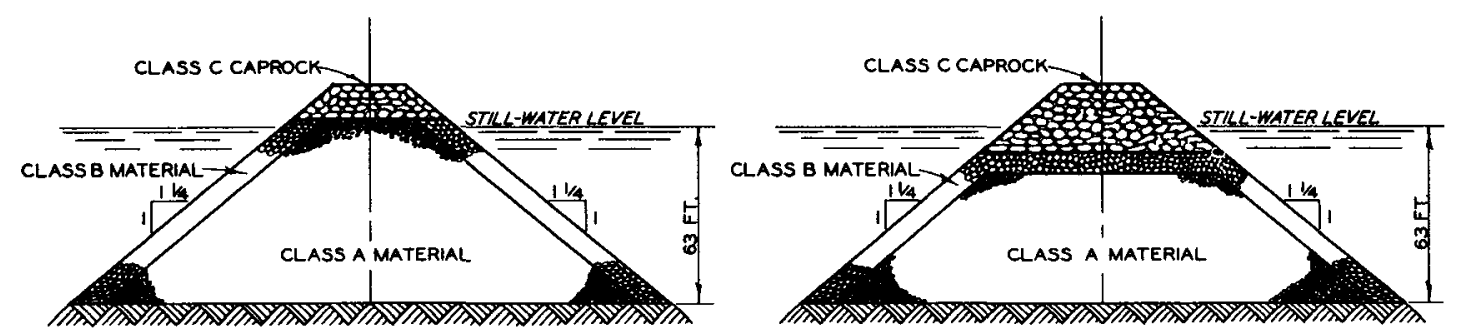

Fig. 3

Breakwater designs tested in model study of breakwater stab1lity, East Beaver Bay Harbor

A comprehensive wind-wave analysis was conducted to determine the dimensions, directions of approach, and frequency of occurrence of waves which would attack the breakwaters. The data and information provided by the model tests and prototype wind-wave analysis were used jointly to estimate the quantity of breakwater material required for maintenance during breakwater construction and for a fortyyear period after construction.

The model design was based on Froude's model laws, and the study conducted in a concrete wave tank, $5 \mathrm{ft}$. deep, $18 \mathrm{ft}$. wide, and $119 \mathrm{ft}$. long, with a $4-\mathrm{ft}$. by 9-ft. glass viewing panel in the wall adjacent to the model breakwater. The breakwaters were placed across the tank, normal to the longltudinal axis, approximately $90 \mathrm{ft}$. from the wave generator; the bottom area at the test section was molded in sand. Model waves were generated by a plunger-type wave machine, and wave helghts were measured and recorded by an electrical apparatus designed and constructed especially for this purpose.

The model breakwaters were constructed in a dry tank, and, after the tank had been flooded to a given depth, the structures were subjected to attack by test wayes of various dimensions unt11 no further displacement of breakwater materials occurred. Soundings were taken frequently to determine the progressive displacement of the breakwater material. Replacement of displaced rock and further subjection to wave attack determined the increased stability gained through the process of damage and repair. 


\section{COASTAL ENGINEERING}

It was concluded from this study that the breakwater constructed by end-dump methods would require about three times as much material for maintenance during construction, and about two and one-half times as much material for maintenance over a 40-year period after construction, as would be required for the conventional-type breakwater. However, because of the difference in the unit costs of handling materials for the two different types of breakwaters, it would be necessary to compare total costs of construction and maintenance over a 40-year period in order to select the most economical breakwater design.

\section{THE MODEL AS A TOOL IN RESEARCH}

Although it is desirable that mathematical expressions, in which all the variables can be handled with relative ease, be avallable to govern the design of breakwaters, the action of wave forces on breakwaters has proven too complex in most instances to be resolved by derived equations of wave motion. Measurements of natural phenomena are desirable, but it is difficult and expensive to obtain adequate data of the required degree of accuracy. These facts suggest the use of models as a research tool to obtain corrective coefficients for available, yet inadequate, theoretical equations, or to formulate empirical equations and design curves. The value of scale models in the development of design criteria can be explained very readily by example. Two types of breakwaters have been selected for this purpose. These are (1) the sloping, rubble-mound breakwater, and (2) the vertical, impervious breakwater. A large number of other breakwater designs are obtained from different combinations of these two types of structures.

\section{DESIGN CRTTERIA FOR RUBBLE BREAKWATERS}

Use of the small-scale model as a research tool excludes the testing of specific structures to obtain the most efficient design. Instead, generalized data are desired which encompass the complete ranges of all the variables involved. After the variables thought to affect the phenomenon have been selected, the research study can proceed in either of two directions: (I) Tests can be conducted in which each variable or dimensionless parameter is varied in turn with the remaining varlables held constant. From the data obtained in this manner, design curves can be prepared which will allow determination of the effects of each variable. Or (2), one of the better available theoretical equations can be revised by application of corrective coefficients obtained from small-scale tests.

Because of the complex action which occurs when waves attack a mound of irregularly shaped and placed rock and the lack of an exact theoretical analysis of the forces involved, it is not feasible to perform tests in which wave pressures on the individual rocks are measured. A very simple method of obtaining the information desired is to perform stability tests of small-scale rubble mounds using different types of rock (size, shape and density), slopes and cross sections of the breakwater, depths of water and wave dimensions ( $H / L$ and $d / L$ ratios), and, by trial and error, to determine the largest wave which does not cause displacement of rock. The research testing program can be guided by dynamic and resistance force expressions based on an idealized picture of the phenomena involved and aided by dimensional reasoning. Thus, by making the necessary simplifying assumptions concerning the forces involved when a wave impinges upon a breakwater rock, the following expressions for dynamic and resistance forces can be obtained:

and

$$
\begin{aligned}
& F_{\mathrm{d}}=\mathrm{k}_{1} \mathrm{w}_{1} \ell^{2} \mathrm{H} \\
& F_{r}=\mathrm{k}_{2}\left(w_{2}-\mathrm{w}_{1}\right) \ell^{3}
\end{aligned}
$$

where $w_{1}$ is the specific weight of the liquid in which the rock is submerged, $w_{2}$ is the specific weight of the rock, $\ell$ is a characteristic linear dimension of the rock. H is wave height, and $k_{1}$ and $k_{2}$ are coefficients, the magnitudes of which are assumed to involve the characteristics of both the waves and the resisting rock structure. These coefficients may include wave steepness (H/L) and $\mathrm{d} / \mathrm{L} \mathrm{ratio}$, breakwater slope $(\varnothing)$, effective coefficient of friction between rock $(\mu)$, void rat1o $\left(v_{r}\right)$, and rock shape factor $(\Delta)$. For incipient instability, $F_{d}=F_{r}$, or 


$$
\frac{w_{1} \ell^{2} H}{\left(w_{2}-w_{1}\right) \ell^{3}}=\frac{k_{2}}{k_{1}}=f\left(\phi, H / L, d / L, \mu, v_{r}, \Delta\right)
$$

Knowing that the individual cap rock weight is $W=\gamma_{\mathrm{r}} \beta$, and substituting in equation 3 the value of $l$ obtained therefrom, it follows that

$$
\frac{w_{1}\left(w_{2}\right)^{1 / 3_{H}}}{\left(w_{2}-w_{1}\right) w^{1 / 3}}=f\left(\phi, H / L, a / L, \mu, v_{r}, \Delta\right)
$$

The results of scale tests can be plotted to show the effects of each variable of the right-hand member of equation 4.

of the existing theories on this subject, that of Irıbarren is, perhaps, the best and most familiar. Iribarren's formula has appeared in several forms (Iribarren, 1949; Hudson, 1950; Epstein, and Tyrrell, 1949) but one which is more general, and dimensionally homogeneous is shown as follows.

$$
w=\frac{k_{3}-w_{1}{ }^{3} w_{2} \mu H^{3} H^{3}}{\left(w_{2}-w_{1}\right)^{3}(\mu \cos \varnothing-\sin \varnothing)^{3}}
$$

In which $\mathrm{k}_{3}$ is an undetermined, dimensionless coefficient.

Preliminary experiments at the Waterways Experiment Station are underway at the present time and have indicated that results might be plotted with $d / I$ as abscissa, $\mathrm{k}_{3}$ as ordinate, and $\varnothing$ as a parameter, producing a family of curves for various slopes. Further testing should indicate more completely the relative importance of variables omitted. In these tests the maximum (design) wave height which did not cause displacement of rock from the face slope was determined. If a slight amount of damage, insufficient to reduce appreciably the efficiency of the breakwater, is allowed, the design wave height can be increased several feet. Design latitude would obviously be increased if data were available for both the nodamage and slight-damage criteria.

\section{DESIGN OF VERTICAL-WALL BREAKWATERS}

Because the function of impervious vertical breakwaters is to reflect rather than absorb the incident waves, the overturning moments resulting from the pressure forces are one of the principal causes of failure. Here, again, there are existing formulas which give wave pressures with varying degrees of accuracy. Notable among these are the formulas of Salnflou, Gourret, Benezit, and Molitor (Hudson, 1950). Since none of these theories defines results of the phenomenon with consistency or with known degrees of accuracy, it is necessary again to modify one of the more accurate and preferably less complicated formulas by experimentation. With these considerations in mind, Sainflou's formula for standing waves is suggested (Sainflou, 1928).

For this type study, data concerning the magnitude and location of standingwave pressures can be taken for various wave dimensions and water depths, and the ratio of measured moments to the Sainflou (1928) theoretical moments can be compared with the various parameters thought to affect the phenomena.

It has been established recently that vertical breakwaters situated in water depths generally considered free from breaking waves may be subjected to localized shock-type pressures more intense than, and possibly in addition to, standing wave pressures. Shock pressures are very difficult to measure in nature, since they are quite erratic and occur only over small areas under certain critical conditions. These critical conditions are more easily obtained in the model, although even this is difficult. Preliminary studies of breaking-wave pressures have been made in England by Bagnold (1938-39) and in the United States by Morison (1948). Additional studies are now in progress at the Beach Erosion Board Laboratory, Corps of Engineers, Department of the Army, Washington, D.C.

\section{CONCLUSIONS}

The experiences of the Armed Forces in World War II showed the inadequacy of the existing science of waves and wave action with relation to engineering struc- 
tures in harbors or on beaches and gave impetus to the development of both theory and experimentation in this fleld. Although there are a considerable number of theoretical works available, as the result of the accelerated pace of investigations brought about by the military situation mentioned above, and although there are quite a number of investigations in progress at the present time, it is hardly possible, yet, to solve any but the most elementary harbor problems by analytical reasoning. Use of the small-scale hydraulic model for solution of specific problems and as a tool in general research is considered to be, therefore, the best approach to the study of harbor wave-action problems, and, in most cases, the costs of such studies are only a small fraction of the prototype installation cost.

\section{REFERENCES}

Arthur, R.S. (1948). Revised wave forecasting graphs and procedures: Scripps Institution of Oceanography, Wave Report No. 73 (unpublished).

Bagnold, R.A. (1938-39). Interim report on wave-pressure research: Jour. Institution of Civil Engineers, vol. 12, pp. 202-226.

Epstein, H., and Tyrell, F.C. (1949). Design of rubble-mound breakwaters: XVII International Navigation Congress, Sec. II, Communication 4, Lisbon, pp. 81-98.

Hudson, R.Y. (1950). Wave forces on breakwaters: Presented at the Annual Meeting of the Amer. Soc. of Civil Engrs., New York, N.Y.

Iribarren Cavanilies, R. (1949). A formula for the calculation of rock fill dikes (Translation): Bulletin of the Beach Erosion Board, vol. 3, pp. 1-16, Corps of Engineers, Washington, D.C.

Johnson, J.W., O'Brien, M.P., and Isaacs, J.D. (1948). Graphical construction of wave refraction diagrams: Hydrographic Office, U.S. Navy, Publ. No. 605.

Keulegan, G.H. (1950a). Engineering hydraulics: Chap. XI, pp. 711-768, John Wiley and Sons, New York, N.Y.

Keulegan, G.H. (1950b). The gradual damping of a progressive oscillatory wave with distance in a prismatic rectangular channel: Report to the Director, Waterways Experiment Station, Vicksburg, Miss.

Lamb, H. (1932). Hydrodynamics, Sixth Edition, Cambridge Univ. Press.

Morison, J.R. (1948). Wave pressures on a vertical wall: Tech. Report HE-116-298, Institute of Engineering Research, University of California, Berkeley, California (unpublished).

Sainflou, G. (1928). Essai sur les digues maritimes verticales: Annales des Ponts et Chaussees, Partie Technique, vol. 98, No. IV, pp. 5-48.

Thorley, T.J. (1950). The use of hydraulic mocels in comprehensive port planning: Presented at the spring Meeting of the Amer. Soc. of Civil Engineers, Los Angeles, Calif.

Waterways Experiment Station, Corps of Engineers (1949a). Wave action and breakwater location, Oswego Harbor, New York - Model Investigation: Tech. Memorandum No. 2-291, Vicksburg, Miss.

Waterways Experiment Station, Corps of Engineers (1949b). Breakwater stability, East Beaver Bay Harbor, Lake Superior, Minnesota - Model Investigation: Tech. Memorandum No. 2-296, Vicksburg, Miss.

Waterways Experiment Station, Corps of Engineers (1949c). Wave and surge action, Long Beach Harbor, Long Beach, California - Model investigation: Tech. Memorandum No. 2-265, Vicksburg, Miss. 